\title{
Identification of novel aberrant methylation of $B A S P 1$ and SRD5A2 for early diagnosis of hepatocellular carcinoma by genome-wide search
}

\author{
TOYOKI MORIBE ${ }^{1}$, NORIO IIZUKA ${ }^{2,3}$, TOSHIAKI MIURA ${ }^{1}$, MARKUS STARK ${ }^{1}$, \\ SHIGERU TAMATSUKURI ${ }^{1}$, HIDEO ISHITSUKA ${ }^{1}$, YOSHIHIKO HAMAMOTO ${ }^{4}$, \\ KAZUHIKO SAKAMOTO ${ }^{2}$, TAKAO TAMESA ${ }^{2}$ and MASAAKI OKA ${ }^{2}$
}

\begin{abstract}
${ }^{1}$ Research Group, Molecular Diagnostics R\&D Department, Roche Diagnostics K.K., 6-1, Shiba 2-chome, Minato-ku, Tokyo 105-0014; Departments of ${ }^{2}$ Digestive Surgery and ${ }^{3}$ Complementary Medicine of Applied Molecular Bioscience, Yamaguchi University Graduate School of Medicine, 1-1-1 Minami-Kogushi, Ube, Yamaguchi $755-8505 ;{ }^{4}$ Department of Computer Science and Systems Engineering, Faculty of Engineering, Yamaguchi University, 2-16-1 Tokiwadai, Ube, Yamaguchi 755-8611, Japan
\end{abstract}

Received May 8, 2008; Accepted July 16, 2008

DOI: 10.3892/ijo_00000082

\begin{abstract}
A genome-wide study using expression profiles of 12,600 genes was conducted to identify methylated genes that could be used for early diagnosis of hepatocellular carcinoma (HCC). Of the 12,600 genes examined, we identified 23 genes with significantly lower expression levels in HCC tissues than in non-HCC liver tissues by our statistical and $\mathrm{CpG}$ mapping tests. Of these 23 genes, methylation analysis by direct sequencing with bisulfite treatment determined 4 genes that were aberrantly methylated in $20 \mathrm{HCC}$ samples of TNM stages I and II. Further methylation analysis of the 4 genes by quantitative sequencing with $20 \mathrm{HCCs}$ and the corresponding non-tumor liver tissues from an independent cohort of HCC patients revealed that 2 genes, BASP1 and SRD5A2, were aberrantly methylated in only HCC tissues, though not in any corresponding non-tumor liver tissues. Notably, in the cohort we found that $B A S P 1$ or $S R D 5 A 2$ were aberrantly methylated when a cut-off value of $30 \%$ in the methylation rate was used, in all cases of 11 HCCs of TNM stages I and II, of 10 welldifferentiated HCCs and of 4 small HCCs $<2 \mathrm{~cm}$ in maximum diameter, but in none of the 20 corresponding non-HCC livers. Methylation-specific PCR for BASP1 and SRD5A2 reproduced the same results observed by direct sequencing. These results
\end{abstract}

Correspondence to: Professor Masaaki Oka, Department of Digestive Surgery of Applied Molecular Bioscience, Yamaguchi University Graduate School of Medicine, 1-1-1 Minami-Kogushi, Ube, Yamaguchi 755-8505, Japan

E-mail: 2geka-1@po.cc.yamaguchi-u.ac.jp

Key words: hepatocellular carcinoma, gene expression database, $\mathrm{CpG}$ island, methylation profiles, BASP1, SRD5A2 indicate that BASP1 and SRD5A2 might serve as useful biomarkers for early diagnosis of HCC.

\section{Introduction}

Hepatocellular carcinoma (HCC), which mainly develops from chronic liver diseases (chronic hepatitis and liver cirrhosis) with persistent infection of the hepatitis $\mathrm{C}$ virus ( $\mathrm{HCV}$ ) and hepatitis B virus $(\mathrm{HBV})$, represents a major international health problem due to an increasing incidence in many countries $(1,2)$. $\mathrm{HCC}$ is also one of the most common fatal cancers worldwide due to the fact that most cases are first diagnosed at an advanced stage since there is no reliable diagnostic test available for detecting HCC among high-risk individuals with chronic hepatitis and liver cirrhosis $(1,2)$. Therefore, a simple and sensitive system for early diagnosis of HCC is urgently needed to improve the outcome of patients with HCC.

Previously, several investigators have proposed that epigenetic inactivation of gene expression linked to aberrant methylation on $\mathrm{CpG}$ islands is a fundamental contributor to carcinogenesis and cancer progression (3-5). Previous clinical studies of the association between abnormal methylation on $\mathrm{CpG}$ islands and carcinogenesis have been conducted in various cancers including HCCs (6-11), supporting the concept that detection of methylation on particular genes in cancer cells may be useful for cancer diagnosis. However, it remains unclear if hypermethylation detection of those genes can be applied to routine clinical use for diagnosis of cancer because previous studies have been limited to looking at only tumor suppressor genes or genes associated with cell proliferation and death (6-11), which should be commonly related to carcinogenesis in various organs and tissues. This genomewide study was conducted to identify methylated genes suitable for use in early diagnosis of HCC in HCV-infected patients and to establish an easy-to-use methylation-specific PCR (MSP) system to measure the methylation status of such genes. 


\section{Materials and methods}

Patients and gene expression database. For identification of novel HCC-specific methylation genes, we examined a 12,600-gene expression database (12) using the Affymetrix Human Genome U95A Gene Chip ${ }^{\circledR}$ (Affymetrix, Inc., Santa Clara, CA), with surgical specimens of 76 tumor and 16 nontumor liver tissues in 76 patients who underwent surgical treatment for HCC at Yamaguchi University Hospital between May 1997 and August 2000. To examine the promoter methylation status of candidate genes in HCC samples that were selected in silico, we used genomic DNA from liver tissue samples of $40 \mathrm{HCC}$ patients independent of the above 76 HCC patients who were subjected to DNA microarray analysis. Subsequently, the $40 \mathrm{HCC}$ patients were divided into 2 subgroups; first round methylation profiling group and second round methylation profiling group (Table I). The first group consisted of 20 tumor samples from 20 patients with HCC of TNM stages I and II. The second group was composed of 20 tumor samples and the corresponding nontumor liver samples (histologically determined as 12 liver cirrhosis, 7 chronic hepatitis and 1 normal liver) from $20 \mathrm{HCC}$ patients. All patients underwent surgical treatment for HCC at Yamaguchi University Hospital between April 2001 and May 2003. The clinicopathological characteristics of these patients based on the International Union against Cancer TNM classification (13) are summarized in Table I. Written informed consent was obtained from all patients before surgery. The study protocol was approved by the Institutional Review Board for Human Use at Yamaguchi University School of Medicine. Histopathological diagnosis of HCC was made after surgery for each case.

Filtering of HCC-specific methylation candidate genes using the gene expression database. To filter HCC-specific methylation genes out of the $\sim 12,600$ in the gene expression database (12), we first selected genes whose signal strength (expression level) was specifically and significantly reduced to half or less in HCC tissues against non-tumor liver tissues by comparing gene expression levels between $76 \mathrm{HCC}$ and 16 non-tumor liver tissues $(\mathrm{p}<0.05)$. The $\mathrm{CpG}$ islands on these genes should be most predominantly methylated in HCC. Then, among the down-regulated genes in HCC tissues, we selected genes carrying $\mathrm{CpG}$ islands in the regions, including promoter and exon 1 (defined as 1,500 bp upstream to 2,200 bp downstream from exon 1 start site, which also included up to 4,000 bp downstream for CYP2E1 which has no CpG island in the promoter) by $\mathrm{CpG}$ mapping analysis using the CpGPlot/ CpGReport/Isochore, a public tool at The European Bioinformatics Institute (EBI) in the European Molecular Biology Laboratory (EMBL) (http://www.ebi.ac.uk/emboss/ cpgplot/). The parameters were set as Obs/Exp (the minimum average observed to expected ratio of $\mathrm{C}$ plus $\mathrm{G}$ to $\mathrm{CpG})=0.6$, MinPC (the minimum average percentage of $\mathrm{G}$ plus $\mathrm{C}$ ) $=50$, and Length (the minimum length that a $\mathrm{CpG}$ island has to be) $=100 \mathrm{bp}$.

Analysis of DNA methylation. For the candidate genes selected by filtering in silico, $1 \mu \mathrm{g}$ of genomic DNA was extracted from tumor tissues of 20 patients with HCC of TNM stages I and II (first round methylation profiling group), as summarized in Table I and 3 commercially available normal liver tissues derived from Asian individuals used as a reference (Male 1/ Female 2, Age: 62.7 \pm 6.1 ; Tissue Transformation Technologies, Inc., Edison, NJ). These extracted DNAs were treated with bisulfite (BIS) for $5 \mathrm{~h}$ at $50^{\circ} \mathrm{C}$ to convert unmethylated cytosine to uracil, as described previously (14-16). BIStreated DNA was quantified as described previously (16) and then was prepared with $75 \mu 1$ of $10 \mathrm{mM}$ Tris-HCl-0.1 mM EDTA solution. After BIS processing, the region including $\mathrm{CpG}$ islands on the candidate genes was amplified by PCR and the methylation status was examined by direct-sequencing using dideoxy chain termination method, using BIS-treated DNA for a template. During this first round methylation profiling, genes unmethylated or methylated poorly at $\mathrm{CpG}$ positions were eliminated from the gene candidate group. Furthermore, of the genes hypermethylated at $\mathrm{CpG}$ positions in HCC samples, genes that were found to be highly methylated in normal liver tissues from healthy individuals were excluded as well. Methylation profiles of the remaining genes were further investigated by pyrosequencing (17), a quantitative sequencing method using the Pyrosequencer PSQ96MA and the Pyro Gold Reagents (Biotag AG, Uppsala, Sweden), in the 20 tumor and the corresponding non-tumor liver tissues from other $20 \mathrm{HCC}$ patients (second round methylation profiling group; see Table I), liver tissues from $2 \mathrm{HCV}$ carriers with chronic hepatitis and liver tissues from 3 healthy individuals. The pyrosequencing results are shown as a Pyrogram (Fig. 1). The methylation rate $(\%)$ at each $\mathrm{CpG}$ position is given by the formula, peak height of Cytosine/(peak height of Cytosine + peak height of thymine) $x 100$. Furthermore, the average of methylation rates at all the examined $\mathrm{CpG}$ positions on candidate genes for each sample was calculated. Genes that had higher average methylation rates in tumor tissues of HCC patients than in both non-tumor liver tissues of HCC patients and liver tissues of HCV carriers, were finally judged as HCC-specific methylation genes. The selected genes were only slightly methylated in liver tissues of healthy individuals as well as in those of $\mathrm{HCV}$ carriers.

PCR amplification of $C p G$ island regions. For sequencing analysis, the region containing $\mathrm{CpG}$ islands of each gene was amplified by PCR with a primer set listed in Table II. The PCR reaction solution was composed of $26.7 \mathrm{ng}$ of BIS-treated DNA, 2 units of rTaq DNA polymerase (Toyobo Co., Ltd, Osaka, Japan) which was pretreated with the equal volume of TaqStart ${ }^{\mathrm{TM}}$ Antibody (Clontech Laboratories, Inc., Mountain View, CA) for $5 \mathrm{~min}$ at room temperature, $67 \mathrm{mM}$ Tris- $\mathrm{HCl}$ (pH 8.8), $16.6 \mathrm{mM}$ ammonium sulfate, $0.01 \%$ Tween-20, $200 \mu \mathrm{M}$ dNTPs, each $1 \mu \mathrm{M}$ of a primer pair and 1.5 or $3 \mathrm{mM}$ magnesium chloride in a final volume of $100 \mu 1$. DNA amplification was performed by using the GeneAmp PCR system 9600 (Applied Biosystems, Foster City, CA) as a PCR amplification instrument by initial denaturation at $95^{\circ} \mathrm{C}$ for 2 min followed by 5 cycles of denaturation at $95^{\circ} \mathrm{C}$ for $25 \mathrm{sec}$, annealing at $70^{\circ} \mathrm{C}$ for $45 \mathrm{sec}$, extension at $72^{\circ} \mathrm{C}$ for $45 \mathrm{sec}$ and followed by 50 cycles of denaturation at $95^{\circ} \mathrm{C}$ for $25 \mathrm{sec}$, annealing at $55^{\circ} \mathrm{C}$ for $50 \mathrm{sec}$, extension at $72^{\circ} \mathrm{C}$ for $45 \mathrm{sec}$. 
Table I. Patient characteristics in this study.

\begin{tabular}{|c|c|c|c|c|}
\hline \multirow[b]{2}{*}{ Patient } & \multirow{2}{*}{$\begin{array}{l}\text { Gene expression } \\
\frac{\text { database }^{\mathrm{a}}}{\mathrm{HCC}(\mathrm{n}=76)}\end{array}$} & \multirow{2}{*}{$\begin{array}{l}\text { 1st round } \\
\text { methylation profiling } \\
\frac{\mathrm{HCC}(\mathrm{n}=20)}{\mathrm{b}}\end{array}$} & \multicolumn{2}{|c|}{$\begin{array}{l}\text { 2nd round } \\
\text { methylation profiling }\end{array}$} \\
\hline & & & $\mathrm{HCC}(\mathrm{n}=20)$ & $\mathrm{HCV}$ carrier $(\mathrm{n}=2)$ \\
\hline \multicolumn{5}{|l|}{ Gender } \\
\hline Male/Female & $54 / 22$ & $15 / 5$ & $13 / 7$ & $0 / 2$ \\
\hline Age (yrs) & $62.1 \pm 9.9$ & $65.2 \pm 8.7$ & $67.3 \pm 7.1$ & $61.5 \pm 3.5$ \\
\hline \multicolumn{5}{|l|}{ Viral infection } \\
\hline $\mathrm{HCV}$ positive & 50 & 19 & 16 & 2 \\
\hline HBV positive & 15 & 1 & 3 & 0 \\
\hline HCV/HBV negative & 11 & 0 & 3 & 0 \\
\hline \multicolumn{5}{|l|}{ Primary lesion } \\
\hline Single tumor & 35 & 14 & 15 & - \\
\hline Multiple tumors & 41 & 16 & 15 & - \\
\hline Tumor size (cm) & $5.0 \pm 4.2$ & $2.7 \pm 0.6$ & $3.9 \pm 3.3$ & - \\
\hline \multicolumn{5}{|l|}{ Stage } \\
\hline $\mathrm{I} / \mathrm{II}$ & 56 & 20 & 11 & - \\
\hline IIIA/IVA/IVB & 20 & 0 & 9 & - \\
\hline \multicolumn{5}{|l|}{ Histological grade } \\
\hline Gl (well-differentiated) & 9 & 5 & 10 & - \\
\hline G2 (moderate-differentiated) & 53 & 14 & 9 & - \\
\hline G3 (poor-differentiated) & 14 & 1 & 1 & - \\
\hline
\end{tabular}

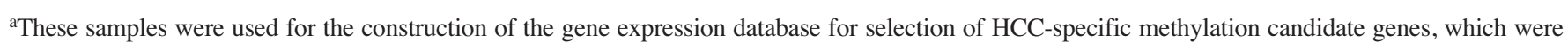
down-regulated specifically in HCC tissues. ${ }^{b}$ These samples were used for 1st round methylation profiling and aberrantly methylated genes in early-stage HCC of TNM stages I and II were selected by the analysis. ${ }^{c}$ These samples were used for 2nd round methylation profiling and specifically methylated genes in HCC tissues but not non-tumor liver tissues and liver tissues of the HCV carrier were selected by the analysis.

The PCR products (351-495 bp) were concentrated using the SUPREC $^{\text {TM }}$-02 (Takara Bio Inc., Otsu, Shiga, Japan) and subjected to electrophoresis on $2 \%$ agarose gel. The target bands of amplified products were excised from gel and isolated using the QIAquick Gel Extraction kit (Qiagen GmbH, Hilden, Germany).

Methylation-specific PCR. Methylation patterns of HCCspecific methylation genes were also confirmed by quantitative real-time methylation-specific PCR (MSP). Briefly, PCR amplification using a primer pair specific to the nucleotide sequence containing methylated cytosines at $\mathrm{CpG}$ positions was performed using the LightCycler ${ }^{\circledR}$ Taq Man master kit for an amplification reagent and the LightCycler ${ }^{\circledR}$ II (Roche Diagnostics GmbH, Mannheim, Germany) for a nucleic acid amplification instrument. For the BASPl gene, the PCR reaction mixture was composed of $5 \mu 1$ of diluted BIS-treated DNA ( $1 \mathrm{ng}), 0.25 \mu \mathrm{M}$ of a primer pair (Forward: 5'-TGTTCGTTTTTTTAGGGTATTC-3', Reverse: 5'-AATT AACCGAAACAACCCG-3') and $0.1 \mu \mathrm{M}$ of Taq Man probe (5'-FAM-ACGCTACTACTTACGAACGCTCGAATAMRA-3') in a final volume of $20 \mu \mathrm{l}$ of $1 \mathrm{x}$ Master mix. PCR amplification was carried out by initial denaturation at $95^{\circ} \mathrm{C}$ for $10 \mathrm{~min}$ followed by 50 cycles of $95^{\circ} \mathrm{C}$ for $10 \mathrm{sec}, 63^{\circ} \mathrm{C}$ for $45 \mathrm{sec}$ and $72^{\circ} \mathrm{C}$ for $5 \mathrm{sec}$ followed by warming of $40^{\circ} \mathrm{C}$ for
30 sec. Fluorescent signal was detected after extension reaction at $72^{\circ} \mathrm{C}$ for each cycle. Amplification of the target gene was monitored by F1/F3 analysis mode in LightCycler software and the amount of methylated DNA in $75 \mu \mathrm{l}$ of BIS-treated DNA solution was quantified using a standard curve made with simultaneously measured standards (dilution series of artificially methylated DNA: at 1000, $200,40$ and $4 \mathrm{pg} / \mu \mathrm{l})$. As for the SRD5A2 gene, the PCR reaction mixture was composed of $5 \mu 1$ of diluted BIS-treated DNA (1 ng), $0.2 \mu \mathrm{l}$ of $2 \mathrm{M}$ potassium acetate ( $\mathrm{pH} 7.5), 0.04 \mu 1$

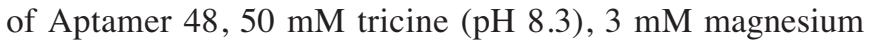
acetate, $375 \mu \mathrm{M}$ dNTPs, $2.5 \%$ glycerol, 0.15 unit ZO5 (thermostable DNA polymerase), $0.4 \mu \mathrm{M}$ of a primer pair (Forward: 5'-AATCGCGTTAGGGTTGGACGC-3', Reverse: 5'-AACGCCAAACGCCACCCG-3') and $0.05 \mu \mathrm{M}$ of Taq Man probe (5'-FAM-ACTCGACCTTAACTCCCGCCCCTTAMRA-3') in a final volume of $20 \mu 1$. PCR amplification was carried out by initial denaturation at $95^{\circ} \mathrm{C}$ for $2 \mathrm{~min}$, followed by 50 cycles of $95^{\circ} \mathrm{C}$ for $15 \mathrm{sec}, 66^{\circ} \mathrm{C}$ for $45 \mathrm{sec}$ and $72^{\circ} \mathrm{C}$ for $5 \mathrm{sec}$, followed by warming of $40^{\circ} \mathrm{C}$ for $30 \mathrm{sec}$. After amplification, the amount of methylated DNA in $75 \mu 1$ of BIS-treated DNA solution was quantified using a standard curve that was made with simultaneously measured standards (dilution series of artificially methylated DNA: at 1000, 200, 50 and $8 \mathrm{pg} / \mu \mathrm{l})$. 

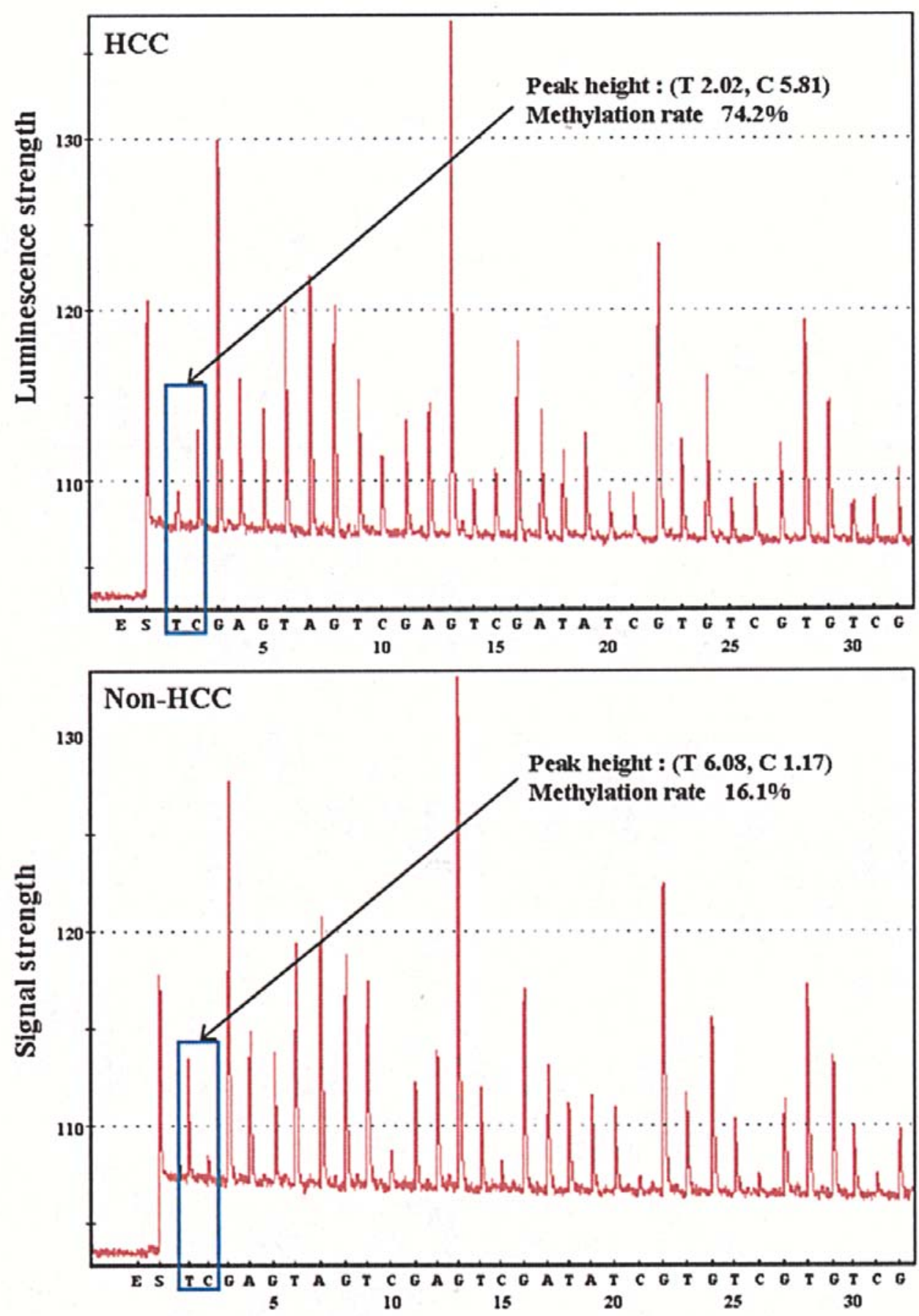

Figure 1. Representative pyrogram for methylation analysis. HCC and non-HCC tissues from an HCC patient were analyzed for SRD5A2 gene. The $y$ - and $x$-axes show luminescence strength and dispensation order (time), respectively. To discriminate methylated cytosine and unmethylated cytosine at the CpG position, $\mathrm{T}$ and $\mathrm{C}$ were dispensed continuously. Peak height was calculated by subtracting the baseline from luminescence strength.

Statistical analysis. Continuous variables were analyzed by the Student's t-test, Mann-Whitney's U test and Welch's t-test. Correlations among data were evaluated by calculating Pearson's correlation coefficient. A value of $p<0.05$ was considered to be statistically significant. Analyses were conducted with Statcel Ver.2 software.

\section{Results}

Novel HCC-specific methylation genes, BASP1 and SRD5A2. Of the $\sim 12,600$ genes on the Affymetrix chip, only $101(0.8 \%)$ were differentially expressed between HCC tissues and non-tumor liver tissues. Out of these 101 genes, $23(0.18 \%)$ carrying $\mathrm{CpG}$ islands in the regions containing promoter and exon 1 were chosen in silico by $\mathrm{CpG}$ mapping analysis (Table II). These genes were then subjected to the methylation profiling step. Among the $23 \mathrm{HCC}$-specific methylation gene candidates, 6 genes which were identified as aberrantly methylated genes in $\mathrm{HCC}, A B C C 9$ (ATP-binding cassette, sub-family C, member 9), APOF (apolipoprotein F), BASP1 (brain abundant, membrane attached signal protein 1), GLS2 (glutaminase 2), HAL (histidine ammonia-lyase) and SRD5A2 


\section{a}

\section{BASP1}
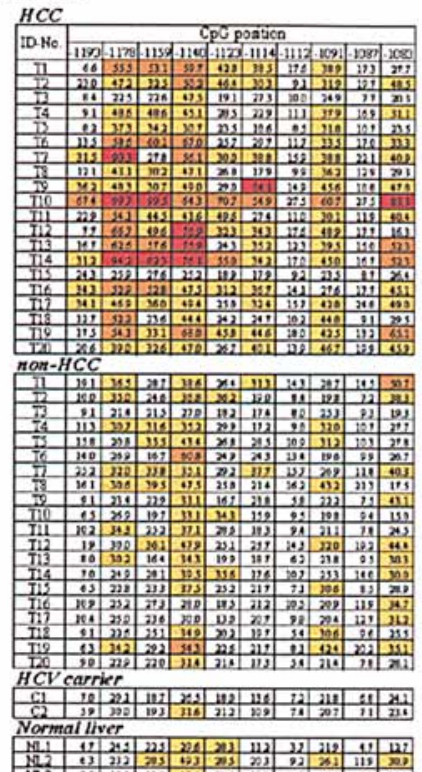

\section{SRDSA2}
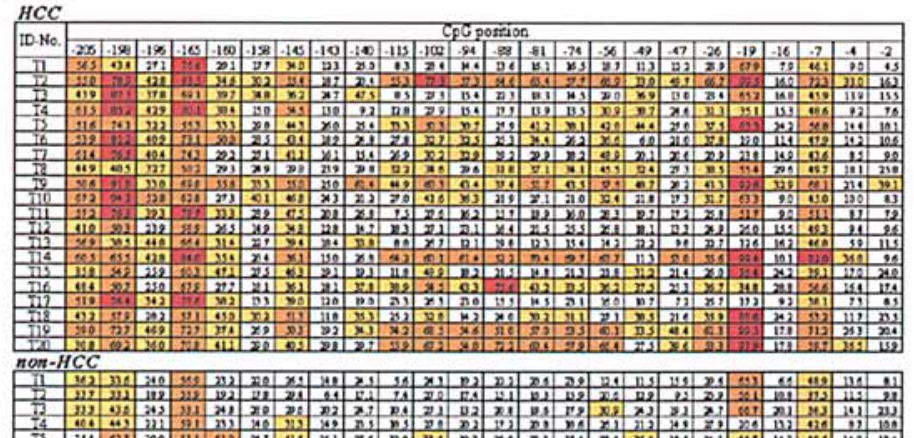



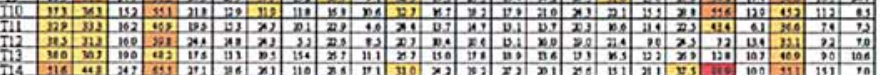

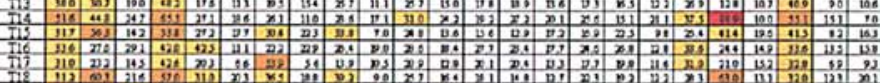

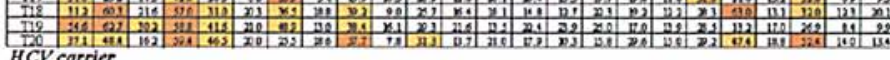





\section{$A B C C 9$}


b

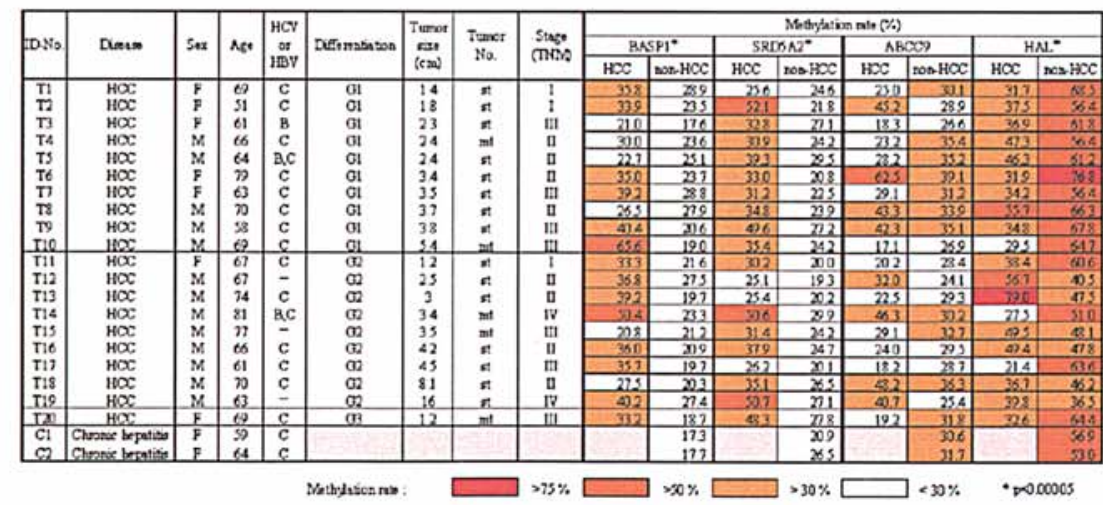

Figure 2. Methylation profiling in HCC and non-HCC tissues for BASP1, SRD5A2, ABCC9 and HAL genes by pyrosequencing. (a) Methylation patterns for 4 genes with HCC and non-tumor liver tissues in second round methylation analysis. Twenty HCC and the corresponding non-HCC tissues from 20 HCC patients (T1-T20) and liver tissues from $2 \mathrm{HCV}$ carriers with chronic hepatitis $(\mathrm{C} 1, \mathrm{C} 2)$ in second round methylation analysis (see Table I) were employed for the analysis. As a reference, normal liver tissues from 3 healthy individuals (NL1-NL3) were also analyzed. Methylation rates are shown in different colors (red $>75 \%$, orange $75-50 \%$, pale orange $50-30 \%$ and white $<30 \%$ ). Position of bisulfite sequencing region was given relative to exon 1 start site. (b) Comparison of average of methylation rates among 4 genes. Average values of methylation rates of all the CpG positions in (a) were calculated for each patient. Methylation rates are shown in different colors as in (a). 


\section{$B A S P 1$}

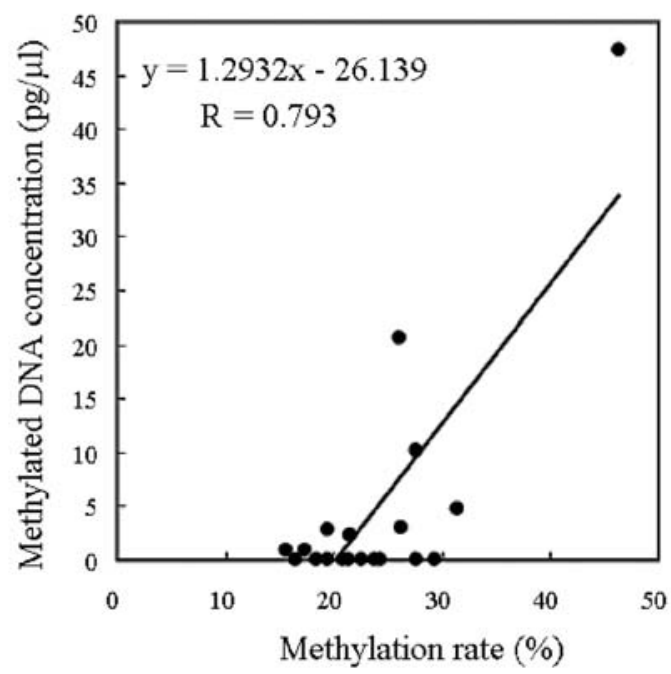

SRD5A2

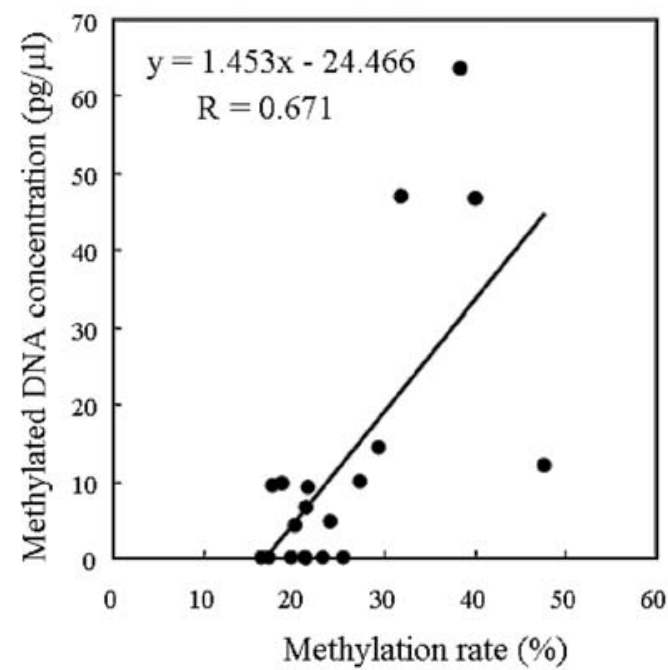

Figure 3. Correlation between the methylated DNA concentration by real-time MSP and the methylation rate by pyrosequencing for BASP1 and SRD5A2. The $y$ - and $x$-axes are the methylated DNA concentration $(\mathrm{pg} / \mu 1)$ and the methylation rate $(\%)$, respectively.

(steroid-5- $\alpha$-reductase, $\alpha$ polypeptide 2 ), were selected in the first round methylation profiling performed using methylation analysis of $\mathrm{CpG}$ islands on genomic DNAs in tumor tissues from 20 patients with HCC of TNM stages I and II. The six genes were further examined in liver tissues from 3 healthy individuals. From this analysis, APOF and GLS2 were excluded due to hypermethylation in normal liver tissues (data not shown). Then, in the second round methylation profiling by comparing methylation profiles of 20 tumor and the corresponding non-tumor liver tissues (12 liver cirrhosis, 7 chronic hepatitis and 1 normal liver) from other $20 \mathrm{HCC}$ patients, liver tissues from $2 \mathrm{HCV}$ carriers with chronic hepatitis and normal liver tissues from healthy individuals, $A B C C 9$ was eliminated because the methylation patterns of tumor tissues of HCC patients were indistinguishable from those of non-tumor liver tissues of HCC patients and the liver tissues of HCV carriers, as shown in Fig. 2a and b. Furthermore, $H A L$ was also excluded due to a much higher methylation rate $(\mathrm{p}<0.00005)$ (Fig. 2b) in non-tumor liver tissues relative to tumor tissues of HCC patients, although this gene was at least more frequently methylated in HCC tissues, than in normal liver tissues from healthy individuals (Fig. 2a). The remaining two genes, $B A S P 1$ and $S R D 5 A 2$, fulfilled the criterion of the HCC-specific methylation gene, because of the definite difference in the extent of methylation of the genes between tumor and non-tumor liver tissues from HCC patients $(\mathrm{p}<0.00005)$ (Fig. 2a and b). These 2 genes were also not extensively methylated in liver tissues of HCV carrier and healthy individuals, with only slight methylation observed on a small part of the $\mathrm{CpG}$ positions (Fig. 2a). In addition, the aberrant methylation of BASP1 or SRD5A2 was positive in $11(100 \%)$ of 11 HCCs of TNM stages I and II, $10(100 \%)$ of 10 well-differentiated HCCs and $4(100 \%)$ of 4 small HCCs of $<2 \mathrm{~cm}$ in maximum diameter, when a cut-off value of $30 \%$ in methylation rate was used in a new cohort of 20 HCC patients (Fig. 2b). By contrast, the aberrant methylation of the 2 genes was not detected in any of the corresponding non-tumor liver tissues (Fig. 2b). There were no significant associations among HCC methylation rates for the 4 genes (BASP1, SRD5A2, ABCC9 and HAL) and gender, age, tumor differentiation, tumor size, tumor number or TNM stages (data not shown).

Methylation analysis by MSP. We confirmed methylation status by quantitative real-time MSP for 19 samples ( 9 sets of tumor and the corresponding non-tumor liver tissues and 1 tumor tissue from 10 HCC patients) that were analyzed by pyrosequencing and examined the correlation between the methylation status analyzed by sequencing and MSP. By Pearson's test the methylated DNA concentration in $75 \mu 1$ of BIS-treated DNA solution measured by MSP was shown to be strongly and significantly correlated with the methylation rate estimated by sequencing analysis $(\mathrm{r}=0.793, \mathrm{p}<0.0001$ and $\mathrm{r}=0.671, \mathrm{p}<0.005$ for $B A S P 1$ and $S R D 5 A 2$, respectively) (Fig. 3).

\section{Discussion}

We have successfully identified 2 aberrantly methylated genes, $B A S P 1$ and SRD5A2, associated with HCC by genome-wide search using gene expression profiles on the Affymetrix GeneChip. To our knowledge, this is the first study screening comprehensively to identify methylated genes for early diagnosis of HCC. Our strategy is justified by the finding that only 2 of 12,600 genes $(0.016 \%)$ fulfilled our selection criteria and neither of the 2 genes have been reported as methylated genes in HCC. BASP 1 was originally identified as a membrane bound protein that is abundant in nerve terminals, with several transient phosphorylation sites and PEST [regions rich in proline $(\mathrm{P})$, glutamate $(\mathrm{E})$ and/or aspartate $(\mathrm{D})$ and serine $(\mathrm{S})$ and/or threonine $(\mathrm{T})$ ] motifs that typically occur in proteins with high turnover rates (18). It has also been reported to be a transcriptional cosuppressor for Wilms' tumor suppressor protein WT1 (19), however, so far there has been no report 


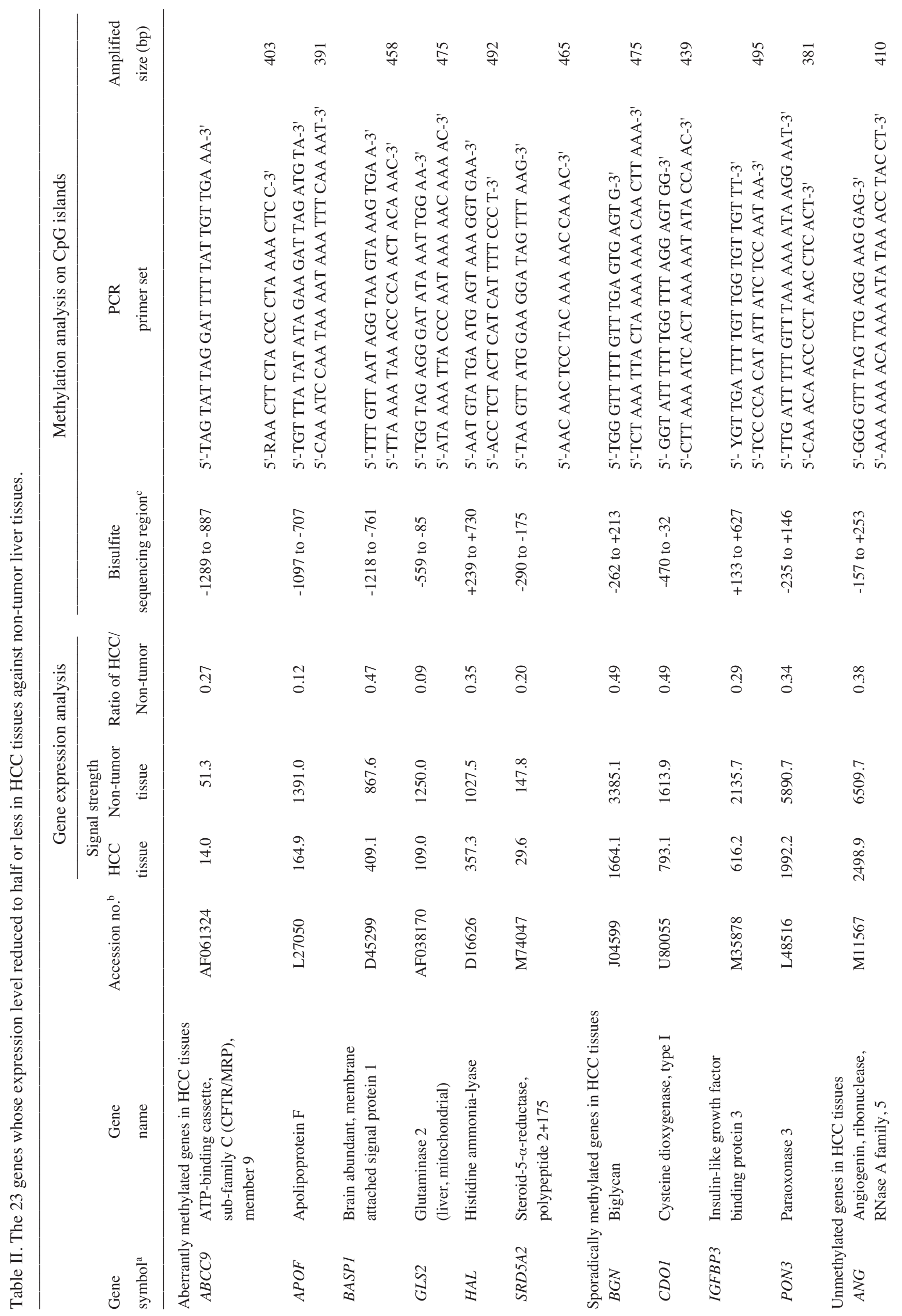







that this protein is correlated with pathogenesis of liver cancer. $S R D 5 A 2$ encodes a microsomal protein expressed at high levels in androgen-sensitive tissues such as the prostate. The encoded protein is a membrane-associated enzyme that catalyzes the conversion of testosterone to dihydrotestosterone (DHT), the most potent androgen in the prostate and the polymorphism and expression level has been shown to be functionally associated with prostate cancer (20-22). To date, it was reported that the SRD $5 A 2$ polymorphism could be associated with liver cancer (23), but no study has been done regarding methylation status in liver tissues. Thus, in this study we were the first to be able to show that BASPI and $S R D 5 A 2$ are exclusively methylated in tumor, but not non-tumor liver tissues from HCC patients and not methylated in any non-tumor liver tissues from $\mathrm{HCV}$ carriers. This suggests that BASP1 and SRD5A2 could be robust biomarkers for diagnosing correctively hepatic nodules arising in $\mathrm{HCV}$-infected patients to be at-risk for HCC. These 2 genes were originally found to be methylated to a certain extent in liver tissues from healthy individuals (Fig. 2a), as reported for some genes by Lehmann et al (11). However, the slightly methylated status was observed to be similar to that of non-tumor and HCV carrier liver tissues in our study. This means BASP1 and SRD5A2 may undergo abnormal methylation only after, or concurrently with developing $\mathrm{HCC}$, regardless of inflammation or fibrosis by $\mathrm{HCV}$ infection.

It is well known that epigenetic changes, including methylation, are related to aging (24). In our present study, no associations were observed between patient age and the methylation status of $B A S P 1$ and SRD5A2. This result might be due in part to the sample size of our present study. To gain insights into our present finding, larger studies are needed.

In our gene expression analysis, expression level of SRD5A2 in HCC tissues was reduced to one-fifth of that in non-tumor liver tissues (Table II), which should be similar to the level found in normal liver tissues from healthy individuals (25). This entrainment profile between high methylation and suppressed gene expression level suggests that SRD5A2 gene expression would be entirely epigenetically inactivated by abnormal methylation of $\mathrm{CpG}$ islands. BASPl was relatively highly expressed in non-tumor liver tissues in our gene expression profiles (Table II), though it has been reported that this gene was not expressed in liver by Western blot analysis (19). Therefore, it could be that mRNA is transcribed, but undergoes only limited translation to protein, possibly due to causes such as fast turnover of mRNA in liver. Expression levels of BASP1 in tumor liver were reduced to half of those found in non-tumor liver (Table II). This may imply that gene expression is not strongly suppressed by methylation. Indeed, our methylation profiling showed that BASP1 was not extensively methylated on $\mathrm{CpG}$ islands, even in HCC tissues, although it was at least more methylated than in non-tumor liver tissues of HCC patients, liver tissues of HCV carriers and normal liver tissues of healthy individuals (Fig. 2a).

$A B C C 9$ and $H A L$ were eliminated through the selection process of HCC-specific methylation genes. Since the 2 genes were found to be strongly methylated in non-HCC tissues and liver tissues of HCV carriers as well as in HCC tissues, although they were not highly methylated in normal liver samples (Fig. 2a and b). For $A B C C 9$, the methylation rate in HCC appeared to be slightly higher than in non-HCC, but they were not statistically different from each other. Interestingly, the methylation rate for $H A L$ in non-HCC was significantly higher than in HCC as shown in Fig. $2 b$ $(\mathrm{p}<0.00005)$. It is inferred from these results that $A B C C 9$ and $H A L$ may be methylated with development or progression of chronic liver diseases with $\mathrm{HCV}$ infection. Furthermore, $H A L$ may undergo demethylation with carcinogenesis.

Most HCCs are initiated as a minute nodule in which cells strongly retain the phenotype of benign hepatocytes. Dysplastic changes, which would mark the transition to a small, welldifferentiated HCC, usually occur when the nodules measure between 1 and $2 \mathrm{~cm}$ in maximal diameter and herald the ability to proliferate, invade and disseminate (26). At this stage, the tumors are easily detected by imaging techniques such as ultrasonography and computed tomography. However, it is not easy to discriminate pathologically well-differentiated HCC from other benign tumors such as dysplasia. Accordingly, the best way for an accurate early diagnosis of this cancer might be to identify the molecular changes that govern the transition to cancer. In this regard, the efficacy of BASP1 and SRD5A2 as tools for early diagnosis of HCC was shown by our present findings that they were aberrantly methylated in all cases of 11 HCCs of TNM stages I and II, of 10 well-differentiated HCCs and of 4 small HCCs $<2 \mathrm{~cm}$ in maximum diameter. Additionally, our developed MSP has made it possible to easily quantify the methylation status of the 2 genes and may enable an early detection of HCC by measuring methylation levels in cell-free DNA circulating in the peripheral blood, although larger studies are needed to evaluate prospectively the diagnostic accuracy of these biomarkers prior to the blood test.

\section{References}

1. El-Serag HB and Mason AC: Rising incidence of hepatocellular carcinoma in the United States. N Engl J Med 340: 745-750, 1999.

2. Okuda K: Hepatocellular carcinoma. J Hepatol 32: 225-237, 2000 .

3. Esteller M, Corn PG, Baylin SB and Herman JG: A gene hypermethylation profile of human cancer. Cancer Res 61: 3225-3229, 2001

4. Jones PA and Baylin SB: The fundamental role of epigenetic events in cancer. Nat Rev Genet 3: 415-428, 2002.

5. Herman JG and Baylin SB: Gene silencing in cancer in association with promoter hypermethylation. N Engl J Med 349: 2042-2054, 2003.

6. Dammann R, Li C, Yoon JH, Chin PL, Bates S and Pfeifer GP: Epigenetic inactivation of a RAS association domain family protein from the lung tumour suppressor locus $3 \mathrm{p} 21.3$. Nat Genet 25: 315-319, 2000.

7. Jin Z, Tamura G, Tsuchiya T, Sakata K, Kashiwaba M, Osakabe $M$ and Motoyama T: Adenomatous polyposis coli (APC) gene promoter hy permethylation in primary breast cancers. Br J Cancer 85: 69-73, 2001.

8. Song JZ, Stirzaker C, Harrison J, Melki JR and Clark SJ: Hypermethylation trigger of the glutathione-S-transferase gene (GSTP1) in prostate cancer cells. Oncogene 21: 1048-1061, 2002.

9. Ku JL, Kang SB, Shin YK, Kang HC, Hong SH, Kim IJ, Shin JH, Han IO and Park JG: Promoter hypermethylation downregulates RUNX3 gene expression in colorectal cancer cell lines. Oncogene 23: 6736-6742, 2004.

10. Yu J, Zhang HY, Ma ZZ, Lu W, Wang YF and Zhu JD: Methylation profiling of twenty four genes and the concordant methylation behaveours of nineteen genes that may contribute to hepatocellular carcinogenesis. Cell Res 13: 319-333, 2003. 
11. Lehmann U, Berg-Ribbe I, Wingen LU, Brakensiek K, Becker T, Klempnauer J, Schlegelberger B, Kreipe H and Flemming P: Distinct methylation patterns of benign and malignant liver tumors revealed by quantitative methylation profiling. Clin Cancer Res 11: 3654-3660, 2005.

12. Iizuka N, Oka M, Yamada-Okabe H, Mori N, Tamesa $\mathrm{T}$, Okada T, Takemoto N, Sakamoto K, Hamada K, Ishitsuka H, Miyamoto T, Uchimura S and Hamamoto Y: Self-organizingmap-based molecular signature representing the development of hepatocellular carcinoma. FEBS Lett 579: 1089-1100, 2005.

13. Sobin LH and Wittekind CH: TNM classification of Malignant Tumours. 6th edition. UICC, Wiley-Liss: pp81-83, 2002.

14. Monroe JJ, Manjanatha MG and Skopek TR: Extent of CpG methylation is not proportional to the in vivo spontaneous mutation frequency at transgenic loci in Big Blue ${ }^{\mathrm{TM}}$ rodents. Mutat Res 476: 1-11, 2001.

15. Tost J, Schatz P, Schuster M, Berlin K and Gut IG: Analysis and accurate quantification of $\mathrm{CpG}$ methylation by MALDI mass spectrometry. Nucleic Acids Res 31: e50, 2003.

16. Iizuka N, Sakaida I, Moribe T, Fujita N, Miura T, Stark M, Tamatsukuri S, Ishitsuka H, Uchida K, Terai S, Sakamoto K, Tamesa $\mathrm{T}$ and Oka M: Elevated levels of circulating cell-free DNA in the blood of patients with hepatitis $\mathrm{C}$ virus-associated hepatocellular carcinoma. Anticancer Res 26: 4713-4719, 2006.

17. ColellaS , Shen L, Baggerly KA, Issa JP and Krahe R: Sensitive and quantitative universal Pyrosequencing methylation analysis of CpG sites. Biotechniques 35: 146-150, 2003.

18. Mosevitsky MI, Capony JP, Skladchikova GY, Novitskaya VA, Plekhanov AYu and Zakharov VV: The BASP1 family of myristoylated proteins abundant in axonal termini: primary structure analysis and physico-chemical properties. Biochimie 79: 373-384, 1997.
19. Carpenter B, Hill KJ, Charalambous M, Wagner KJ, Lahiri D, James DI, Andersen JS, Schumacher V, Royer-Pokora B, Mann M, Ward A and Roberts SG: BASP1 is a transcriptional cosuppressor for the Wilms' tumor suppressor protein WT1. Mol Cell Biol 24: 537-549, 2004.

20. Makridakis NM, Ross RK, Pike MC, Crocitto LE, Kolonel LN, Pearce CL, Henderson BE and Reichardt JK: Association of mis-sense substitution in SRD5A2 gene with prostate cancer in African-American and Hispanic men in Los Angeles, USA. Lancet 354: 975-978, 1999.

21. Nam RK, Toi A, Vesprini D, Ho M, Chu W, Harvie S, Sweet J, Trachtenberg J, Jewett MA and Narod SA: V89L polymorphism of type-2, 5-alpha reductase enzyme gene predicts prostate cancer presence and progression. Urology 57: 199-205, 2001.

22. Luo J, Dunn TA, Ewing CM, Walsh PC and Isaacs WB: Decreased gene expression of steroid 5 alpha-reductase 2 in human prostate cancer: implications for finasteride therapy of prostate carcinoma. Prostate 57: 134-139, 2003.

23. Rossi L, Leveri M, Gritti C, De Silvestri A, Zavaglia C, Sonzogni L, Silvestri L, Civardi E, Mondelli MU and Silini EM: Genetic polymorphisms of steroid hormone metabolizing enzymes and risk of liver cancer in hepatitis $\mathrm{C}$-infected patients. J Hepatol 39: 564-570, 2003.

24. Liu L, Wylie RC, Andrews LG and Tollefsbol TO: Aging, cancer and nutrition: the DNA methylation connection. Mech Ageing Dev 124: 989-998, 2003

25. Thigpen AE, Silver RI, Guileyardo JM, Casey ML, McConnell JD and Russell DW: Tissue distribution and ontogeny of steroid 5 alpha-reductase isozyme expression. J Clin Invest 92: 903-910, 1993.

26. Bruix J, Boix L, Sala M and Llovet JM: Focus on hepatocellular carcinoma. Cancer Cell 5: 215-219, 2004. 